\title{
Laser Stimulation and Observation of Elementary Chemical Reactions in the Gas Phase
}

\author{
K. KLEINERMANNS and J. WOLFRUM
}

Max Planck-Institut für Strömungsforschung, 3400 Göttingen, Böttingerstraße 4-8, West Germany and Physikalisch-Chemisches Institut der Ruprecht-KarlsUniversität Heidelberg, 6900 Heidelberg, Im Neuenheimer Feld 253, West Germany

The paper describes experimental investigations using UV and IR molecular lasers for selective translational, vibrational and electronic excitation in gas phase radical reactions.

The nascent $\mathrm{OH}$ rotational, vibrational and fine structure state distributions produced in the endothermic reactions

$$
\mathrm{H}+\mathrm{O}_{2}, \mathrm{CO}_{2}, \mathrm{H}_{2} \mathrm{O} \longrightarrow \mathrm{OH}(K, v, f)+\mathrm{O}, \mathrm{CO}, \mathrm{H}_{2}
$$

were measured by laser induced fluorescence at collision energies of $251 \mathrm{~kJ} / \mathrm{mol}$ with hot $\mathrm{H}$ atoms from the photo-dissociation of $\mathrm{HBr}$ at $193 \mathrm{~nm}$. By monitoring reactant and product densities at short times, absolute cross sections of

$$
\begin{aligned}
\sigma_{\mathrm{H}-\mathrm{O}_{2}} & =0.42 \pm 0.2 \AA^{2} \quad \sigma_{\mathrm{H}-\mathrm{CO}_{2}}=0.37 \pm 0.1 \AA^{2} \\
\sigma_{\mathrm{H}-\mathrm{H}_{2} \mathrm{O}} & =0.24 \pm 0.1 \AA^{2} \text { were obtained. }
\end{aligned}
$$

After single quantum excitation of the $\mathrm{C}-\mathrm{F}$ stretching vibration $\left(\nu_{3}\right)$ in $\mathrm{CH}_{3} \mathrm{~F}$ with a $\mathrm{CO}_{2}$ laser pathways for collision induced mode selective energy transfer into $\mathrm{C}-\mathrm{H}$ bending and stretching modes and the effect of mode selective excitation on the reaction

$$
\mathrm{Br}+\mathrm{CH}_{3} \mathrm{~F}(\nu) \longrightarrow \mathrm{HBr}+\mathrm{CH}_{2} \mathrm{~F}
$$

were observed.

The laser induced radical chain elimination of hydrogen chloride from 1,2dichlorethane (DCE) forming vinyl chloride (VC) has been studied in a flow reactor in the temperature range from $470-720 \mathrm{~K}$. Product formation after the laser pulse was observed time-resolved with a UV-absorption technique. The rate constant of the decomposition of the 1,2-dichloroethyl radical

$$
\mathrm{C}_{2} \mathrm{H}_{2} \mathrm{Cl} \stackrel{+M}{\longrightarrow} \mathrm{C}_{2} \mathrm{H}_{3} \mathrm{Cl}+\mathrm{Cl}
$$


was measured to

$$
k_{5}=(6.5 \pm 2) \cdot 10^{13} \exp \left(-83 \pm 3 \mathrm{~kJ} \mathrm{~mol}^{-1} / \mathrm{RT}\right) \mathrm{s}^{-1}
$$

Effects of temperature, pressure and initial radical concentration of quantum yields and on $k_{5}$ were determined.

\section{INTRODUCTION}

Traditionally the energy dependence of chemical reaction rates is characterized by thermal Arrhenius parameters. These parameters contain, however, no direct information how the various degrees of freedom in the reacting molecules and in the "activated complex" contribute to the overcoming of the potential energy barrier of the chemical reaction. The development of modern coherent light sources has provided a number of new possibilities to obtain information on chemical reactivity as a function of specific excitation on the reactants. Such experiments can give direct insights into microscopic dynamics of chemical reactions which is the basis for new ways to drive chemical reactions more selectively than by thermal heating. The paper discusses the effect of selective translational, vibrational and electronic excitation in simple radical reactions in the gas phase. Experimental results obtained with excimer laser generated translationally hot, and thermal radicals, and vibrational excitation of molecules by infrared lasers are compared with results obtained by theoretical calculations.

\section{TRANSLATIONAL EXCITATION: DYNAMICS AND ABSOLUTE CROSS SECTIONS OF SOME ENDOTHERMIC HYDROGEN ATOM REACTIONS AT HIGH COLLISION ENERGIES}

The technique of flash photolysis for production of hot atoms in conjunction with time-integrated product detection methods has long been used to get information about reaction cross sections and excitation functions. Especially the reactions of hot hydrogen atoms and its isotopes with saturated hydrocarbons, $\mathrm{D}_{2}, \mathrm{CO}_{2}, \mathrm{~N}_{2} \mathrm{O}$ and others have been investigated. In all these experiments the measured reaction yields could only be deconvoluted to reaction probabilities or cross sections with guesses about the collisional cooling processes of the 
hot atoms. However, for most chemically interesting reactions, little is known about the detailed inelastic scattering processes.

We want to introduce a new method to study the dynamics of high barrier reactions combining hot atom and radical production by laser photolysis (high monoenergetic collision energies) and time-resolved product detection by laser induced fluorescence or other sensitive time and state resolved detection techniques.

We investigated the reactions

$$
\begin{array}{cc}
\mathrm{H}+\mathrm{O}_{2} \longrightarrow \mathrm{OH}(v, K, f)+\mathrm{O} & \Delta H=16.6 \mathrm{kcal} / \mathrm{mol} \\
\mathrm{H}+\mathrm{CO}_{2} \longrightarrow \mathrm{OH}(v, K, f)+\mathrm{CO} & \Delta H=25.4 \mathrm{kcal} / \mathrm{mol} \\
\mathrm{H}+\mathrm{H}_{2} \mathrm{O} \longrightarrow \mathrm{OH}(v, K, f)+\mathrm{H}_{2} & \Delta H=14.8 \mathrm{kcal} / \mathrm{mol}
\end{array}
$$

The reactions are important in combustion systems as chain branching steps and in the $\mathrm{CO}$ oxidation.

We report nascent $\mathrm{OH}$ rotational, vibrational and fine structure state distributions as well as absolute reaction cross sections for the three reactions.

The apparatus used has been described in detail elsewhere. ${ }^{1}$ The $\mathrm{OH}$ state distribution is measured by combining Excimer laser photolysis of rapidly flowing $\mathrm{HBr}$ and $\mathrm{O}_{2}$ mixtures with laser induced fluorescence detection of the $\mathrm{OH}$ product at a short time after the photolysis pulse scanning the $\mathrm{OH}\left(X^{2} \Pi\right) \longrightarrow \mathrm{OH}\left(A^{2} \Sigma\right)$ transition from 3060 to $3160 \AA$. (See Figure 1). Since the $R$-branch heads contain lines from $v=0, K=3$ to $v=0, K=18$, in the region 3063 to $3078 \AA$, and from $V=1, K=1$ to $v=1, K=14$ in the region 3129 to $3121 \AA$, a large number of states could be examined while maintaining experimental conditions. Above $v=0, K=18$ and $v=1$, $K=14$ the scatter in the data is larger and was minimized by repeated scans.

Normally relative peak heights above the base line were converted to relative $\mathrm{OH}$ densities by dividing the intensity by the laser power and the appropriate Hönl-London ${ }^{2}$ and Franck-Condon factors. ${ }^{3}$ In some of the spectral scans the $\mathrm{OH}$ absorption was driven to saturation so that the LIF intensity is independent of variations of the laser power and directly proportional to $\mathrm{OH}$ density.

For the reaction $\mathrm{H}+\mathrm{O}_{2}$, only the $v, K$ levels shown in Figure 2 could be observed by LIF due to predissociation in the upper $\mathrm{OH}\left({ }^{2} \Sigma\right)$ 


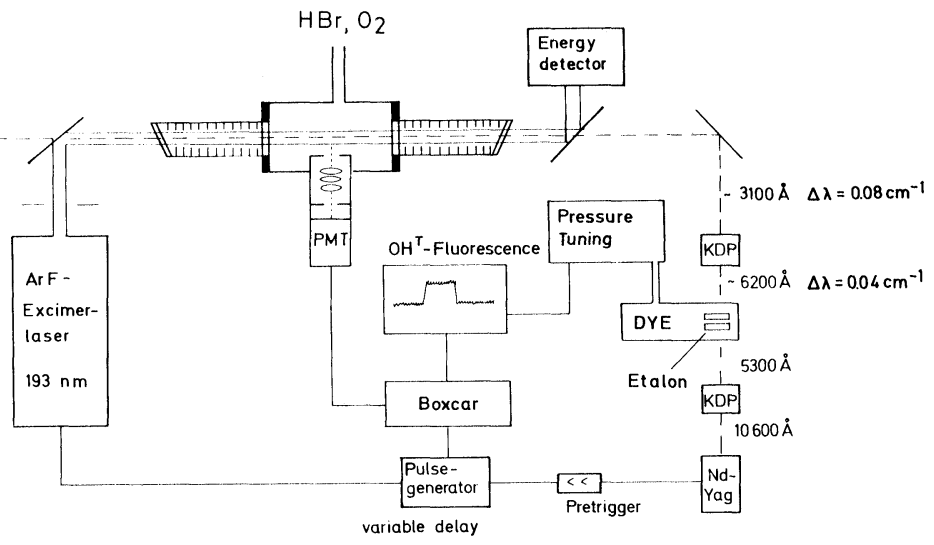

FIGURE 1 Schematic of the experimental arrangement for the study of radical reactions with substantial threshold energies by combining Excimer Laser photolysis and fast product detection with laser induced fluorescence.

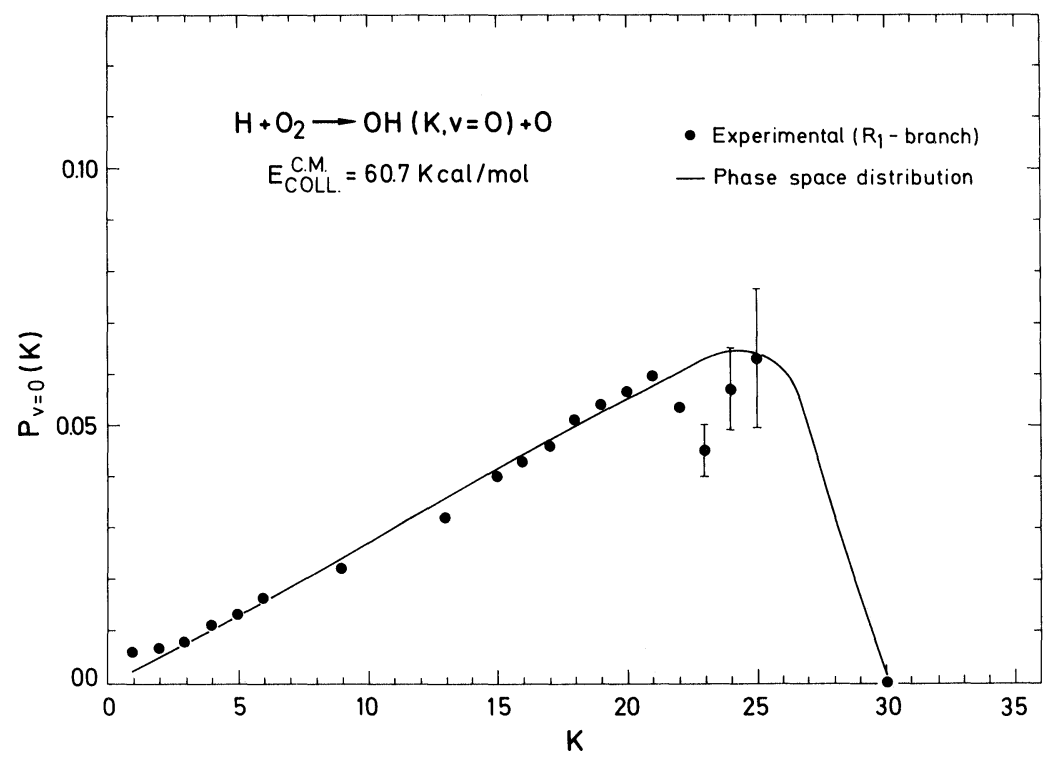

FIGURE 2 Comparison of the measured rotational state distribution $(\bullet)$ in $\mathrm{OH}(v=$ 0 ) produced in the reaction (1) with the phase space statistical distribution (-). 
state. The data for this reaction have been corrected for predissociation. ${ }^{4}$ The points $K=30$ in $v=0$ and $K=27$ in $v=1$ are necessarily zero by energy conservation for the $\mathrm{H}-\mathrm{O}_{2}$ reaction. The narrow dip in the $v=0$ distribution does result from collision induced predissociation in $\mathrm{OH}\left({ }^{2} \Sigma\right)$ in the region of the ${ }^{4} \Sigma^{-}$curve crossing ${ }^{4}$ and not from reaction.

The absorption of $\mathrm{HBr}$ between 2500 and $1600 \AA$ is continuous. Photolysing $\mathrm{HBr}$ at $1932 \AA$ the primary process appears to be the production of the ground state $\mathrm{Br}$ atoms ${ }^{2} P_{3 / 2}{ }^{5}$

$$
\mathrm{HBr} \stackrel{193 \mathrm{~nm}}{\longrightarrow} \mathrm{H}^{\tau}+\mathrm{Br}\left({ }^{2} \mathrm{P}_{3 / 2}\right)
$$

The translational energy of the fragments in the c.m. system is $E=$ $h \nu-D_{0}(\mathrm{H}-\mathrm{Br})=61.5 \mathrm{kcal} / \mathrm{mol}$ of which the $\mathrm{H}$ atoms carry $80 / 81$. Accordingly the velocity of the $\mathrm{H}$ atoms is

$$
V_{\mathrm{H}}=3.2 \cdot 10^{6} \mathrm{~cm} / \mathrm{sec}
$$

with the $\mathrm{Br}$ atoms nearly at rest with respect to them.

The relative velocity in the c.m. system of the hot hydrogen atoms colliding with room temperature $\mathrm{O}_{2}$ molecules is

$$
g^{2}=v_{\mathrm{H}}^{2}+v_{\mathrm{O}_{2}}^{2}-2 v_{\mathrm{H}} v_{\mathrm{O}_{2}} \cos \vartheta \simeq v_{\mathrm{H}^{\tau}}^{2}
$$

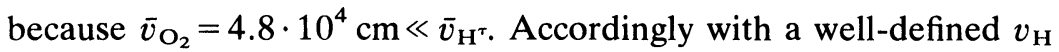
we have initially a monoenergetic collision energy.

$$
E_{\text {coll }}^{\text {c.m. }}=60.7 \mathrm{kcal} / \mathrm{mol}
$$

Similar collision energies are obtained for the reactions $\mathrm{H}+\mathrm{H}_{2} \mathrm{O}$ and $\mathrm{H}+\mathrm{CO}_{2}$.

\section{Rotational partitioning}

At collision energies of $60 \mathrm{kcal} / \mathrm{mol}$ all three endothermic reactions are relatively fast. Typically $\mathrm{OH}$ spectra could be taken at a probe time of $100 \mathrm{~ns}$ at typical partial pressures $5 \mathrm{~m}$ torr $\mathrm{HBr}, 50 \mathrm{~m}$ torr $\mathrm{O}_{2}$, $\mathrm{CO}_{2}, \mathrm{H}_{2} \mathrm{O}$. At these pressures the gas kinetic collision frequency between the hot $\mathrm{H}$ atoms and $\mathrm{O}_{2}$ is $8 \cdot 10^{6} \mathrm{~s}^{-1}$. At a probe time of $100 \mathrm{~ns}$, less than one collision should have occurred between the hot hydrogen atoms and the gas and less than 0.1 collisions between the $\mathrm{OH}$ product molecules and the gas. 
Figure 3 presents typical portions of spectra obtained in the $R$ branch head of $\mathrm{OH}, v=0$ under approximately single collision conditions. The corresponding rotational state distributions are given in Figure 4 . Both probe times and total pressures were varied between 40-140 ns and 50 and $200 \mathrm{~m}$ torr without noticeable change in the form of the spectra due to rotational relaxation effects.

$$
\begin{aligned}
\mathrm{H}^{\top}+\mathrm{O}_{2} \rightarrow \mathrm{OH}(\mathrm{K}, \mathrm{v}, \mathrm{f})+\mathrm{O} \quad & \mathrm{R}_{1}-\text { branch } \\
& E_{\mathrm{coL}}^{\mathrm{CM}}=607 \mathrm{Kcal} / \mathrm{mol} \\
& \mathrm{P}_{02}=190 \mathrm{~m} \mathrm{torr} \\
& t=40 \mathrm{n} \mathrm{sec}
\end{aligned}
$$
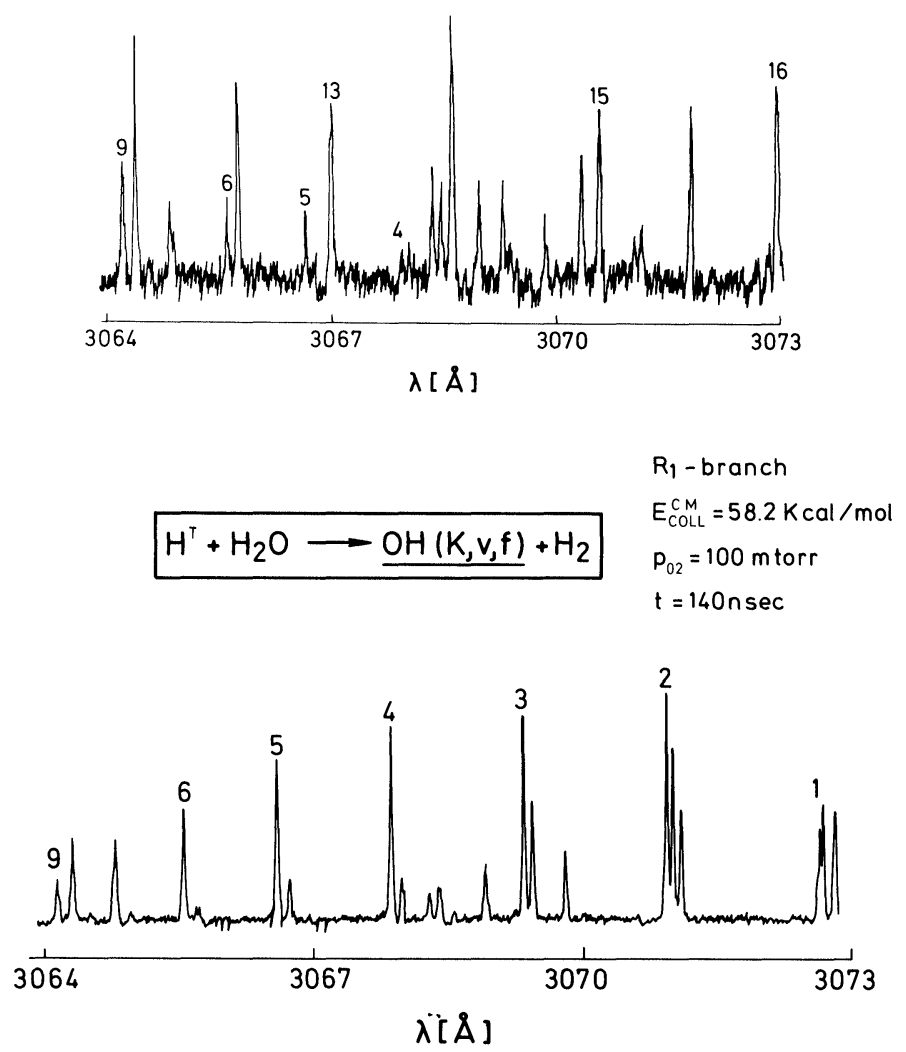

FIGURE 3 (a) Part of the rotational spectrum in $\mathrm{OH}(v=0)$ produced in the reaction (1). (b) Part of the rotational spectrum in $\mathrm{OH}(v=0)$ produced in the reaction (3). 


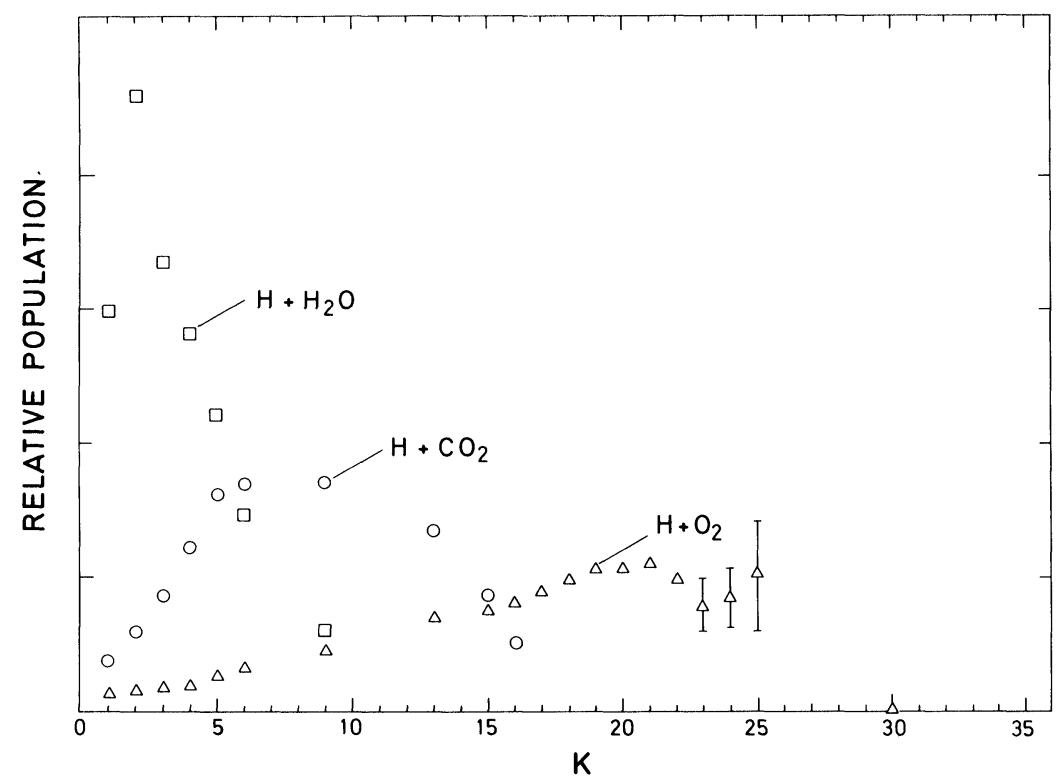

FIGURE 4 Nascent rotational state distributions in $\mathrm{OH}(v=0)$ produced in the reactions $(\square) \mathrm{H}+\mathrm{H}_{2} \mathrm{O} \rightarrow \mathrm{OH}+\mathrm{H}_{2},(\mathrm{O}) \mathrm{H}+\mathrm{CO}_{2} \rightarrow \mathrm{OH}+\mathrm{CO},(\triangle) \mathrm{H}+\mathrm{O}_{2} \rightarrow \mathrm{OH}+\mathrm{O}$ $K$ is the rotational quantum number.

The most striking result is that the $\mathrm{OH}$ rotational distribution from the $\mathrm{H}-\mathrm{O}_{2}$ reaction is extremely hot, while the $\mathrm{H}-\mathrm{H}_{2} \mathrm{O}$ reaction leads to little rotational excitation despite comparable total energies of $\simeq 44 \mathrm{kcal} / \mathrm{mol}$ for both reactions. Obviously the dynamics and the potential surfaces for the two reactions are very different.

The reaction $\mathrm{H}\left({ }^{2} S\right)+\mathrm{O}_{2}\left({ }^{3} \Sigma_{g}^{-}\right) \rightarrow \mathrm{OH}\left({ }^{2} \Pi\right)+\mathrm{O}\left({ }^{3} P\right)$ is known to take place adiabatically on the ground state potential energy surface of $\mathrm{HO}_{2}\left({ }^{2} A^{\prime \prime}\right)$. The $\mathrm{HO}_{2}$ complex is $54 \mathrm{kcal} / \mathrm{mol}^{11}$ stable relative to the reactant region of the surface. Because of this deep $\mathrm{HO}_{2}$ potential well it seems adequate to compare the measured rotational distribution with a statistical distribution. Since the reaction has angular momentum constraints, phase space theory ${ }^{7}$ is the most appropriate statistical model for comparison with the experimental results. While the $\mathrm{H}+\mathrm{H}_{2} \mathrm{O}$ reaction leads to a very nonstatistical rotational distribution, phase space and measured rotational distribution are in good agreement for the $\mathrm{H}-\mathrm{O}_{2}$ reaction (Figure 2). 
However, care must be taken to conclude from this resemblance the existence of a long living $\mathrm{HO}_{2}$ complex at these high collision energies. We performed trajectory calculations on an ab initio $\mathrm{H}-\mathrm{O}_{2}$ potential surface ${ }^{8}$ and got rotational distributions in very good agreement with the experimental ones. The calculation showed us, that no long living $\mathrm{HO}_{2}$ complex exists at $60 \mathrm{kcal} / \mathrm{mol}$ collision energy. Typical residence times in the complex region are on the order of $10^{-15} \mathrm{~s}$ with only a few reflections (2-4 on the average) on the potential walls before entering the product or reactant region respectively.

\section{Vibrational partitioning}

Despite the high collision energies, no $\mathrm{OH}(v=1)$ could be observed from the reactions $\mathrm{H}+\mathrm{H}_{2} \mathrm{O}$ and $\mathrm{H}+\mathrm{CO}_{2}$. Earlier investigations ${ }^{11}$ have shown, that the reaction $\mathrm{OH}+\mathrm{CO} \rightarrow \mathrm{H}+\mathrm{CO}_{2}$ could not be vibrationally accelerated by excitation of $\mathrm{OH}$ to $v=1$.

Also for $\mathrm{OH}(v=1)+\mathrm{H}_{2} \rightarrow \mathrm{H}_{2} \mathrm{O}+\mathrm{H}$ the enhancement is less than a factor of $1.5^{11}$ relative to the ground state reaction, while $\mathrm{H}_{2}(v=1)$ is reported ${ }^{12}$ to react 150 times more rapidly with $\mathrm{OH}$ than $\mathrm{H}_{2}(v=0)$. It may be mentioned here that the $\mathrm{OH}$ bond distance remains almost constant going from $\mathrm{OH}$ to $\mathrm{H}_{2} \mathrm{O}$.

As shown in Table $\mathrm{I}$, the reaction $\mathrm{H}+\mathrm{O}_{2}$ leads to substantial vibrational excitation. Since not all of the rotational states could be observed here due to predissociation, vibrational partitioning is taken from the observed linear rotational surprisals $\mathbf{s}^{10}$ in $v=0$ and $v=1$. The measured vibrational excitation $\sigma(v=1) / \sigma(v=0)=0.45 \pm 0.15$ is somewhat lower than the phase space statistical expectation 0.71 .

\section{Fine structure partitioning}

Spin-orbit and orbital-rotation interactions in the ${ }^{2} \Pi$ state cause fine structure splittings for each rotational level. Each of these fine structure levels can be probed by different rotational subbands, i.e., $\Pi_{1}^{+}$ by $P_{1}$ or $R_{1}, \Pi_{1}^{-}$by $Q_{1}, \Pi_{2}^{+}$by $P_{2}$ or $R_{2}$ and $\Pi_{2}^{-}$by $Q_{2},{ }^{13}$ so that cross sections for production of the sublevels can be determined separately.

The results are given in Table II. While the spin doublets are produced statistically, there is a preference for the $\Pi^{+} \Lambda$-doublet component in all three reactions. The preference increases somewhat 
TABLE I

Observed vibrational partitioning into $\mathrm{OH}$ from the reactions $\mathrm{H}+$ $\mathrm{H}_{2} \mathrm{O}, \mathrm{CO}_{2} \mathrm{O}_{2} \rightarrow \mathrm{OH}+\mathrm{H}_{2}, \mathrm{CO}, \mathrm{O}$ at $60 \mathrm{kcal} / \mathrm{mol}$ collision energy

\begin{tabular}{llll}
\hline & $\mathrm{H}+\mathrm{H}_{2} \mathrm{O}$ & $\mathrm{H}+\mathrm{CO}_{2}$ & $\mathrm{H}+\mathrm{O}_{2}$ \\
\hline$\frac{\sigma(v=1)}{\sigma(v=0)}$ & $\leqslant 0.1$ & $\leqslant 0.1$ & $0.47 \pm 0.15$ \\
\hline
\end{tabular}

with $K$ and approaches the values of Table II at the highest populated $K$.

For high rotational states, the electron density of the singly occupied $\mathrm{OH} \Pi$ orbital forms lobes either in the rotation plane $\left(\Pi^{+}\right)$or perpendicular to it. ${ }^{14}$ Adiabatically the $\Pi$ orbital points along the direction of the bond that is broken during the course of the reaction. The results show that all three reactions generate a torque in a plane containing the bond to be broken, i.e., that the exit channels of the reactions occur in a plane. If the reactions could somehow generate a torque about the bond to be broken, $\mathbf{J}_{\mathrm{OH}}$ would be parallel to the $\Pi$ orbital and the $\Pi^{-}$state preferentially populated. Preference for the $\mathrm{OH} \Pi^{+}$state has been found before ${ }^{15}$ in several chemical reactions leading to $\mathrm{OH}$.

\section{Absolute reaction cross sections}

In case of monoenergetic collision energies the change of $\mathrm{OH}$ density in the internal state $i$ is

$$
\frac{d\left[\mathrm{OH}_{i}\right]}{d t}=\sigma_{i}(g) \cdot g \cdot[\mathrm{H}]_{t} \cdot[\mathrm{B}]
$$

TABLE II

Observed fine structure partitioning for rotational levels of $\mathrm{OH}(v=0)$ produced in the reactions $\mathrm{H}+\mathrm{H}_{2} \mathrm{O}, \mathrm{CO}_{2}, \mathrm{O}_{2} \rightarrow \mathrm{OH}+\mathrm{H}_{2}, \mathrm{CO}, \mathrm{O}$ at $60 \mathrm{kcal} / \mathrm{mol}$ collision energy

\begin{tabular}{cccc}
\hline & $\mathrm{H}+\mathrm{H}_{2} \mathrm{O}$ & $\mathrm{H}+\mathrm{CO}_{2}$ & $\mathrm{H}+\mathrm{O}_{2}$ \\
\hline$\frac{\sigma\left({ }^{2} \Pi_{3 / 2}\right)}{\sigma\left({ }^{2} \Pi_{1 / 2}\right)} \cdot \frac{K}{K+1}$ & $1.1 \pm 0.2$ & $1.2 \pm 0.2$ & $1.2 \pm 0.2$ \\
$\frac{\sigma\left(\Pi^{+}\right)}{\sigma\left(\Pi^{-}\right)}$ & $3.2 \pm 1.0$ & $3.0 \pm 1.0$ & $5.9 \pm 1.0$ \\
\hline
\end{tabular}


with [B] as the $\mathrm{O}_{2}, \mathrm{CO}_{2}, \mathrm{H}_{2} \mathrm{O}$ concentration respectively and [B] 》 $[\mathrm{H}], g \simeq v_{\mathrm{H}}, \sigma_{i}$ as state specific cross section averaged in our experiment over the room temperature vibrational and rotational distribution of $[\mathrm{B}]$ and $[\mathrm{H}]_{t}$ as hydrogen atom density as function of time.

To avoid or reduce collisional cooling of the hot $\mathrm{H}$ atoms the spectra have to be taken at essentially single collision conditions with just a small fraction of the $\mathrm{H}$ atoms reacted. Then $[\mathrm{H}]_{t} \simeq[\mathrm{H}]_{0}$ and

$$
\sigma \simeq \frac{\sum_{i}\left[\mathrm{OH}_{i}\right]_{t}}{[\mathrm{H}]_{0}}\left(v_{\mathrm{H}} \cdot[\mathrm{B}] \cdot t\right)^{-1}
$$

The $\mathrm{OH}$-detection sensitivity is calibrated via $\mathrm{HNO}_{3}$ photodissociation. For small photolysis laser absorptions we obtain

$$
\begin{aligned}
{[\mathrm{OH}]^{\mathrm{HNO}_{3}} } & =\left[\mathrm{HNO}_{3}\right] \cdot I_{0} \cdot \sigma_{\mathrm{HNO}_{3}} \\
{[\mathrm{H}]_{0} } & =[\mathrm{HBr}] \cdot I_{0} \cdot \sigma_{\mathrm{HBr}} \\
{[\mathrm{HBr}] } & =\left[\mathrm{HNO}_{3}\right] \\
{[\mathrm{H}]_{0} } & =[\mathrm{OH}]^{\mathrm{HNO}_{3}} \cdot \frac{\sigma_{\mathrm{HBr}}}{\sigma_{\mathrm{HNO}_{3}}}
\end{aligned}
$$

with $\sigma_{\mathrm{HBr}}=1.7 \cdot 10^{-18} \mathrm{~cm}^{2},{ }^{16} \sigma_{\mathrm{HNO}_{3}}=1.06 \cdot 10^{-17} \mathrm{~cm}^{217}$ and $I_{0}$ as photolysis laser photonflux.

Then

$$
\sigma \simeq \frac{\left[\mathrm{OH}_{j}\right]_{t}}{\left[\mathrm{OH}_{j}\right]^{\mathrm{HNO}_{3}}} \cdot \sum_{i} \frac{\left[\mathrm{OH}_{i}\right]_{t}}{\left[\mathrm{OH}_{j}\right]_{t}} / \sum_{i} \frac{\left[\mathrm{OH}_{i}\right]^{\mathrm{HNO}_{3}}}{\left[\mathrm{OH}_{j}\right]^{\mathrm{HNO}_{3}}} \cdot\left(v_{\mathrm{H}} \cdot[\mathrm{B}] \cdot t \cdot \frac{\sigma_{\mathrm{HBr}}}{\sigma_{\mathrm{HNO}_{3}}}\right)^{-1}
$$

and the summation is over all rotational, vibrational and fine structure states of $\mathrm{OH}$.

Despite being somewhat cumbersome, this procedure has the advantage of reducing the determination of absolute $[\mathrm{OH}]_{t}$ and $[\mathrm{H}]_{0}$ concentrations to the determination of relative $\mathrm{OH}$ distributions which can be determined quite exactly by repeated spectral scans under various conditions.

The cross sections in Table III have been obtained with $v_{\mathrm{H}}=$ $3.2 \times 10^{6} \mathrm{~cm} / \mathrm{s}$, [B] densities typically $1.6-4.8 \times 10^{15}\left[\mathrm{~cm}^{-3}\right](50-$ $150 \mathrm{~m}$ torr) and reaction times $40-140 \mathrm{n} \mathrm{s}$. For the $\mathrm{H}-\mathrm{O}_{2}$ reaction the $v=2$ and $v=3 \mathrm{OH}$ densities have been estimated from the vibrational surprisal leading to the somewhat higher uncertainty for this reaction. 
TABLE III

Absolute reaction cross sections for the reaction $\mathrm{H}+\mathrm{H}_{2} \mathrm{O}, \mathrm{CO}_{2}, \mathrm{O}_{2} \rightarrow \mathrm{OH}+$ $\mathrm{H}_{2}, \mathrm{CO}, \mathrm{O}$ at high collision energies and room temperature $\mathrm{H}_{2} \mathrm{O}, \mathrm{CO}_{2}$ and $\mathrm{O}_{2}$

\begin{tabular}{lccc}
\hline & $\mathrm{H}+\mathrm{H}_{2} \mathrm{O}$ & $\mathrm{H}+\mathrm{CO}_{2}$ & $\mathrm{H}+\mathrm{O}_{2}$ \\
\hline$E_{\text {coll }}^{\text {c.m. }}[\mathrm{kcal} / \mathrm{mol}]$ & 58.2 & 60.1 & 60.7 \\
$\sigma\left[\AA^{2}\right]$ & $0.24 \pm 0.1$ & $0.37 \pm 0.1$ & $0.42 \pm 0.2$ \\
\hline
\end{tabular}

The combination of hot atom production and fast product detection seems to be a versatile tool to get information about the dynamics and cross sections of chemical reactions with substantial energy barriers.

Nascent $\mathrm{OH}$ state distributions produced in the endothermic reactions of $\mathrm{H}\left({ }^{2} S\right)$ with $\mathrm{O}_{2}, \mathrm{CO}_{2}$ and $\mathrm{H}_{2} \mathrm{O}$ have been measured at $60 \mathrm{kcal} / \mathrm{mol}$ collision energy. Despite comparable total energies the $\mathrm{OH}$ rotational distributions from the reactions $\mathrm{H}+\mathrm{O}_{2}$ and $\mathrm{H}+\mathrm{H}_{2} \mathrm{O}$ are drastically different implying different dynamics. The $\mathrm{OH}$ rotational distribution produced in the $\mathrm{H}-\mathrm{O}_{2}$ reaction is very similar to the statistical distribution, but quasi classical trajectory calculations show that the reaction proceeds very fast at $60 \mathrm{kcal} / \mathrm{mol}$ collision energy with only femtoseconds residence time in the $\mathrm{HO}_{2}$ complex region. In all three reactions the $\Pi^{+} \Lambda$ doublet component is preferentially populated demonstrating essentially planar exit channels. Relatively small cross sections have been measured for the three reactions at $60 \mathrm{kcal} / \mathrm{mol}$ collision energy.

Further experimental work will be directed to study the doppler profiles of the hot hydrogen atoms with a tunable $L \alpha$-laserlight source $^{18}$ and to measure the reaction cross sections at different collision energies by varying the photolysis wavelength. The measurements will be compared with quasi classical trajectory calculations on $a b$ initio and model surfaces to get more information about the widely unknown dynamics of high barrier chemical reactions.

\section{VIBRATIONAL EXCITATION: COLLISION INDUCED MODE SELECTIVE ENERGY TRANSFER IN METHYLFLUORIDE}

In order to obtain information about the bimolecular chemical reaction of a polyatomic molecule which is excited in a specific vibrational 
mode one must first try to decouple the vibrational energy exchange from the removal of the excited molecule by interaction with the added reactant. Using a low partial pressure of the excited molecules and spectral and time resolved detection of the infrared emission from the different excited modes a direct observation of the energy flow is possible. For such investigations substituted methanes are well suited molecules. A great deal of information concerning vibration to vibration energy transfer has been obtained for the molecule $\mathrm{CH}_{3} \mathrm{~F}$ mainly due to the pioneering studies of Flynn and coworkers ${ }^{19}$ using laser induced infrared fluorescence, infrared double resonance, and time resolved thermal lensing experiments. A higher detection sensitivity for the laser induced fluorescence could be achieved in our experiments by a Welsh type mirror system for the collection of the infrared photons and two plane mirrors for multiple reflection of the exciting $\mathrm{CO}_{2}$-laser beam. This gave an improvement of a factor 25 compared to fluorescence cells without collecting mirrors. The TEA $\mathrm{CO}_{2}$-laser used is grating tuned to the $P(20)$ line at $1048.85 \mathrm{~cm}^{-1}$ and excites the $\nu_{3} \mathrm{C}-\mathrm{F}$ stretching mode of $\mathrm{CH}_{3} \mathrm{~F}$. Cooled $\mathrm{LiF}$ and $\mathrm{MgF}_{2}$ windows, several interference filters, and $\mathrm{GeHg}(4 \mathrm{~K})$ and $\mathrm{InSb}$ $(77 \mathrm{~K})$ detectors were used for time and spectral resolved fluorescence monitoring. The signal to noise ratio is improved by a transient recorder combined with a signal averaging system. With the $\mathrm{CO}_{2}$-laser pulses used $(200 \mathrm{~ns}, 500 \mathrm{~mJ})$ a fraction of 0.4 from the $\mathrm{CH}_{3} \mathrm{~F}$ molecules is excited to the $\nu_{3}(v=1)$ level. The activation of several vibrational modes in $\mathrm{CH}_{3} \mathrm{~F}$ was studied by measuring the rise time of the fluorescence in the levels $2 \nu_{3}$ (overtone of the pumped $\nu_{3}$ level) at $2082 \mathrm{~cm}^{-1}, \nu_{6}(\mathrm{C}-\mathrm{H}$ bend $)$ at $1181 \mathrm{~cm}^{-1}, \nu_{2}, \nu_{5}(\mathrm{C}-\mathrm{H}$ bend $)$ at $1460 \mathrm{~cm}^{-1}$ and $\nu_{1}, \nu_{4}(\mathrm{C}-\mathrm{H}$ stretch $)$ around $3000 \mathrm{~cm}^{-1}$.

After single quantum excitation of the $\mathrm{C}-\mathrm{F}$ stretching vibration $\nu_{3}$ at $1049 \mathrm{~cm}^{-1}$ vibrational energy is transferred first via "up the ladder" processes in the pumped $\nu_{3}$ mode. Only four gas kinetic collisions are required in the nearly resonant vibration-to-vibration energy transfer process. Local Coriolis resonances between the $3 \nu_{3}$ and the $\nu_{4}$ level at high rotational states ${ }^{20}$ allow a small fraction of population in the $2 \nu_{3}$ level to enter the $\nu_{4}$ level. If the time resolved fluorescence signals are studied as a function of added inert gas pressure with the partial pressure of $\mathrm{CH}_{3} \mathrm{~F}$ kept constant the intensity of the emission from the $\mathrm{C}-\mathrm{H}$ bending $\left(\nu_{6}, \nu_{5}, \nu_{2}\right)$ and $\mathrm{C}-\mathrm{H}$ stretching $\left(\nu_{1}, \nu_{4}\right)$ levels increases drastically (see Figure 5). This can be 


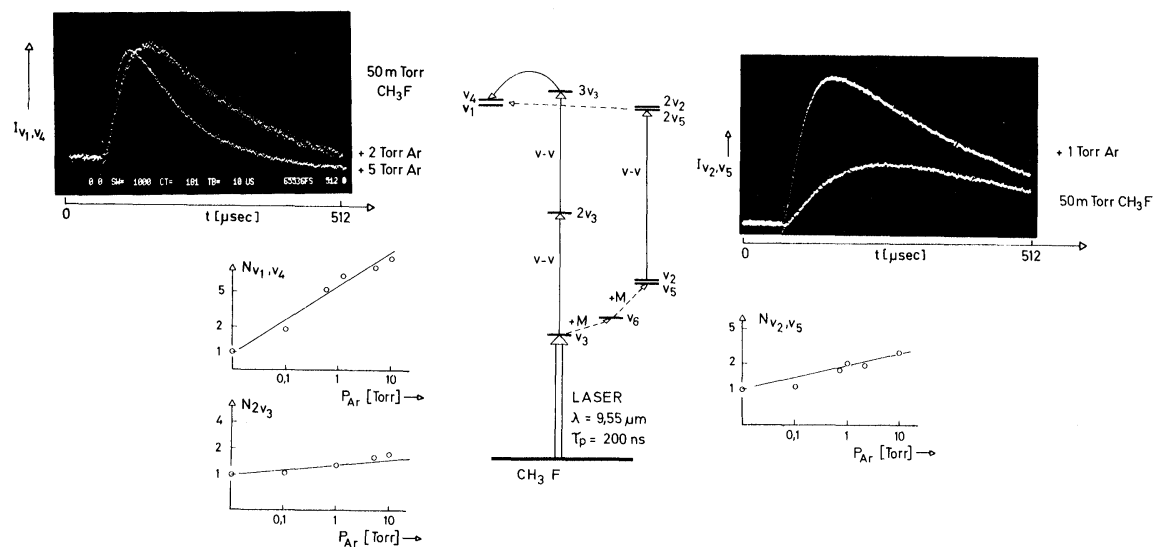

FIGURE 5 Vibrational energy level diagram of $\mathrm{CH}_{3} \mathrm{~F}$ with the different pathways for the collision induced intramolecular energy transfer.

explained by another dominant pathway under these conditions. The intermode energy gaps between $\nu_{3}, \nu_{6}$ and $\nu_{2}, \nu_{5}$ are surmounted in collisions of the excited $\mathrm{CH}_{3} \mathrm{~F}\left(\nu_{3}\right)$ molecules with inert gas atoms. Since the overtone $2 \nu_{2}$ is in the Fermi resonance with $\nu_{1}$ an efficient population of the $\mathrm{C}-\mathrm{H}$ stretching vibration is also possible. The experiments show, that a "metastable" vibrational energy distribution with dominant population in the $\mathrm{C}-\mathrm{F}$ stretching mode can be created after laser excitation. While the total vibrational energy in the excited $\mathrm{CH}_{3} \mathrm{~F}$ molecule remains nearly constant the distribution can be changed in a mode selective way by collisions with inert gas atoms.

As shown in Figure 6 the reaction

$$
\mathrm{Br}+\mathrm{CH}_{3} \mathrm{~F} \longrightarrow \mathrm{HBr}+\mathrm{CH}_{2} \mathrm{~F}
$$

can be used as model system for a study of the mode specific energy consumption in reactions of vibrationally excited polyatomic molecules. The experiments were carried out in an arrangement shown in Figure 7.

A high sensitivity for a time-resolved detection of the reaction product $\mathrm{HBr}$ was achieved by using a tunable diode laser for infrared resonance absorption spectroscopy and a White-cell design for extension of the absorption path. The reaction volume was increased 


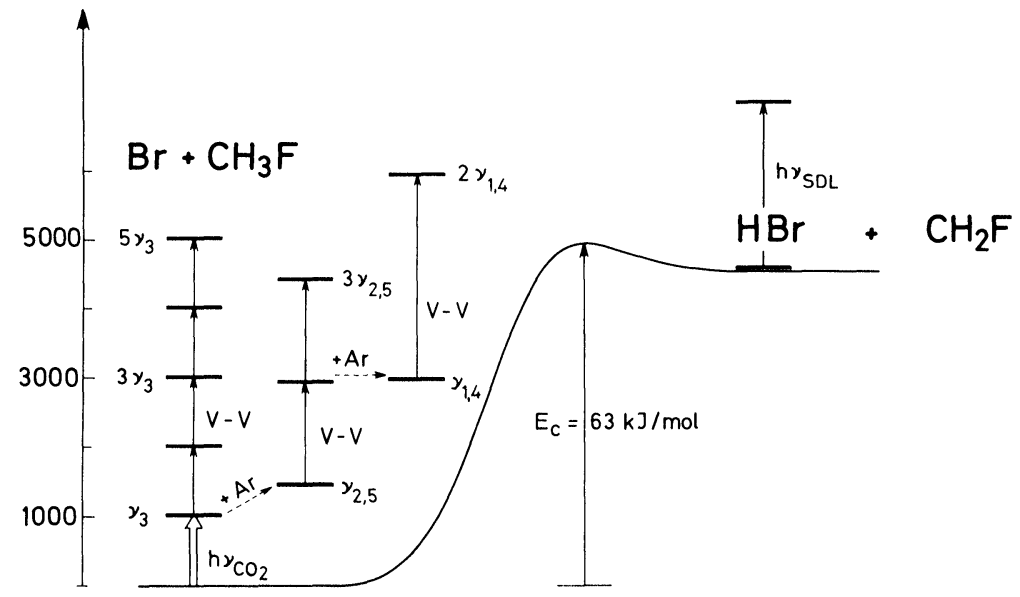

FIGURE 6 Experimental diagram for the reaction of vibrationally excited $\mathrm{CH}_{3} \mathrm{~F}$ molecules with $\mathrm{Br}$ atoms.

by multiple reflection of the exciting $\mathrm{CO}_{2}$-laser beam between two plane mirrors. The experiments indicate that the $\mathrm{C}-\mathrm{F}$ vibration $\nu_{3}$ excited by the laser pulse is much less effective for reaction (4) than $\mathrm{C}-\mathrm{H}$ vibrations populated by collision induced mode selective energy transfer.

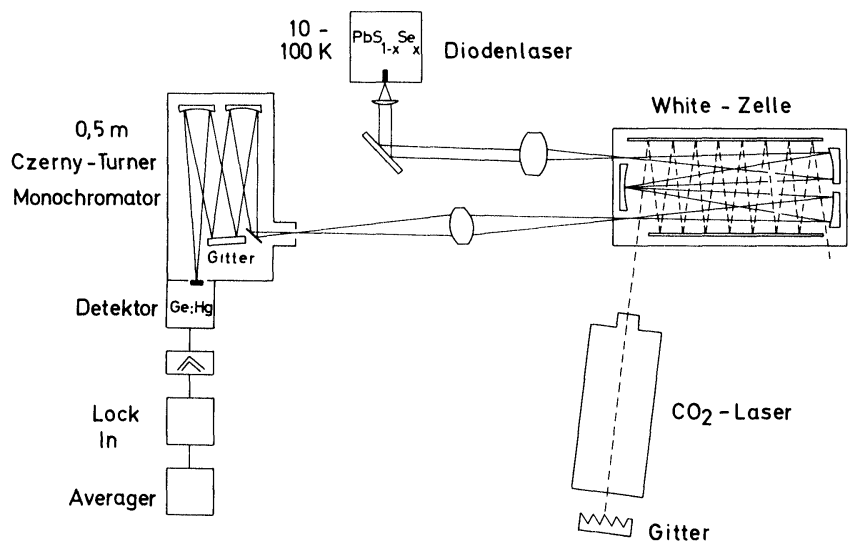

FIGURE 7 Experimental arrangement for time-resolved product detection from reactions of $\mathrm{CO}_{2}$ laser excited molecules by tunable infrared diode laser spectroscopy. 


\section{ELECTRONIC EXCITATION: FORMATION OF $\mathrm{C}_{2} \mathrm{H}_{3} \mathrm{Cl}$ BY LASER-INDUCED RADICAL CHAIN REACTIONS}

The special properties of rare-gas halide ( $\mathrm{RGH})$ lasers such as defined energy, wavelength and beam geometry, together with a short pulse length have opened numerous new ways for a specific electronic excitation of molecules. ${ }^{21}$ This work describes the application of the RGH laser to investigate the mechanism and kinetics of the photoinitiated chain reaction of 1,2-dichlorethane (DCE) to form vinyl chloride (VC). ${ }^{22}$ The reaction is of considerable industrial importance, being the main route to production of vinyl chloride monomer feedstock for PVC manufacture.

As shown in Figure 8 the experiments were made using a cyclindrical fused quartz flow reactor with suprasil windows. The reactor was closely fitted in an aluminium tube enclosed in a temperaturecontrolled oven. A temperature gradient less than $1 \%$ along the reactor axis was observed. The photolysis source was a LambdaPhysik EMG 501 laser operated at $193 \mathrm{~nm}(\mathrm{ArF}), 222 \mathrm{~nm}(\mathrm{KrCl})$, $248 \mathrm{~nm}(\mathrm{KrF})$ and $306 \mathrm{~nm}(\mathrm{XeCl})$. Time resolved product analysis was made by UV-absorption measurements with a $\mathrm{HgXe-lamp,} \mathrm{a}$ $0.15 \mathrm{~m}$ monochromator (Oriel 7240 ) for preselection before the cell,

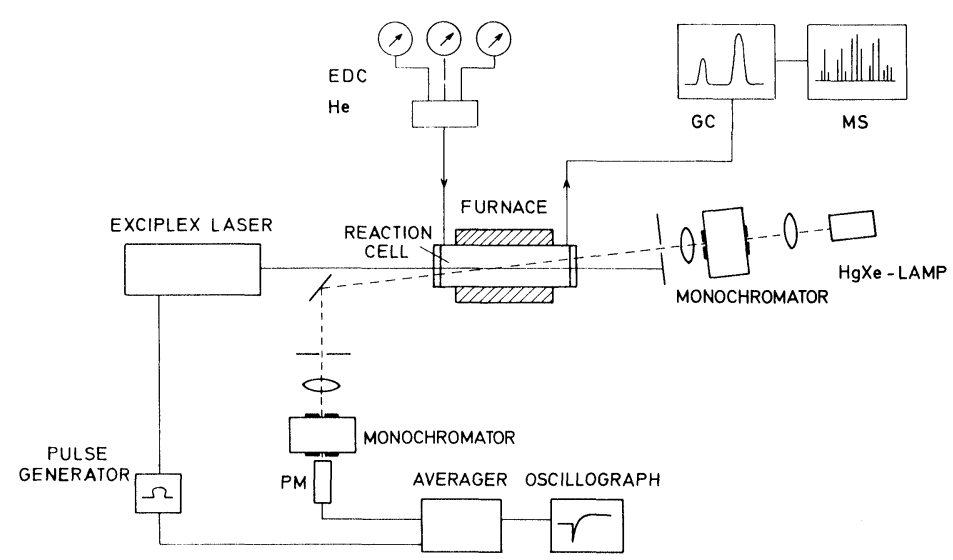

FIGURE 8 Experimental arrangement for the investigation of laser induced radical chain reactions by product detection with time resolved UV-spectroscopy combined with gas chromatographic and mass spectrometric analysis. 
a second monochromator ( $0.3 \mathrm{~m}$, Zeiss MW3) behind the cell and a photomultiplier (EMI, 6256A) as detector. In addition gas samples extracted from the reaction cell by gas syringe were analysed by gas chromatography, mass spectrometry and in an infrared sample cell.

The results of absorption measurements for DCE are plotted semilogarithmically against wavelength in Figure 9. A steep rise of the absorption cross section with shorter wave length and increasing temperature is observed. However, very small absorption cross sections were found below $250 \mathrm{~nm}$. Nevertheless substantial amounts of vinyl chloride can be formed after irradiation with the $\mathrm{KrF}$ and $\mathrm{XeCl}$ laser lines. In order to study this effect more quantitatively a series of experiments was carried out varying the laser energy per pulse from 10 to $250 \mathrm{~mJ}$ at fixed photolysis wave length, temperature and DCE pressure. In a double logarithmic plot of quantum yield versus initial radical concentration (see Figure 10) one obtains a straight line with a slope of -0.5 . This negative square root dependence of the quantum yield can be explained by a Rice-Herzfeld mechanism. ${ }^{23}$ The elementary steps involved are shown in Figure 11. Good agreement is obtained between the measured and calculated rate of vinyl chloride formation.

An additional series of experiments was performed to study the temperature dependence of the quantum yield at a constant conversion rate per laser shot. This has the advantage of working with

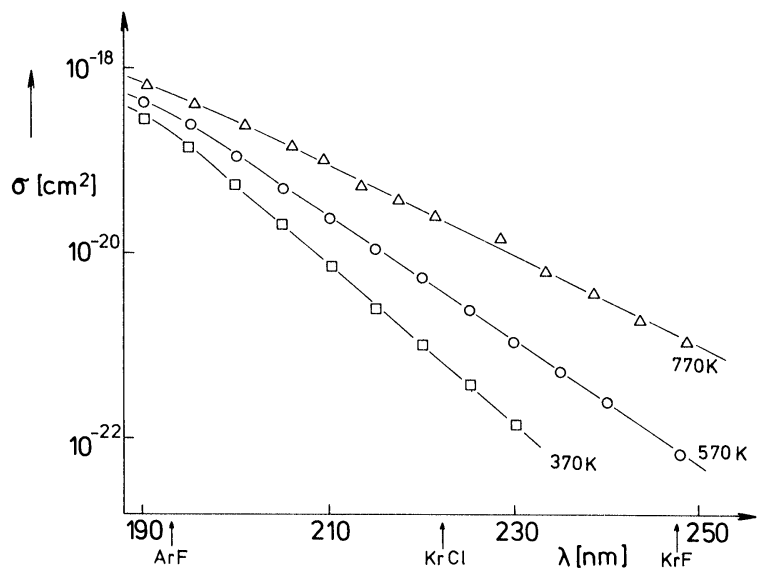

FIGURE 9 UV-Absorption of 1,2-dichlorethane at different temperatures. 


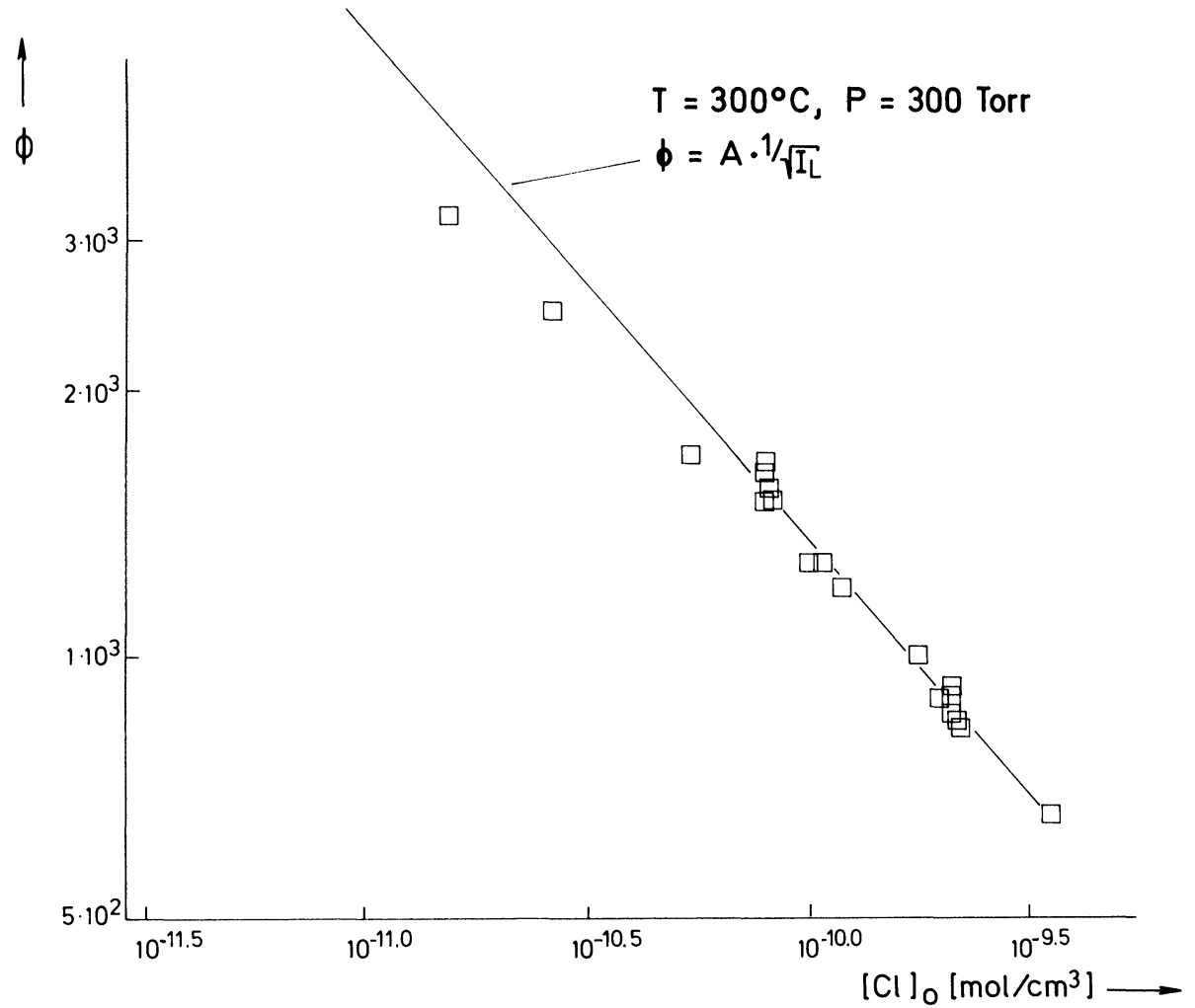

FIGURE 10 Quantum yield of $\mathrm{C}_{2} \mathrm{H}_{3} \mathrm{Cl}$ formation as function of initial radical concentration.

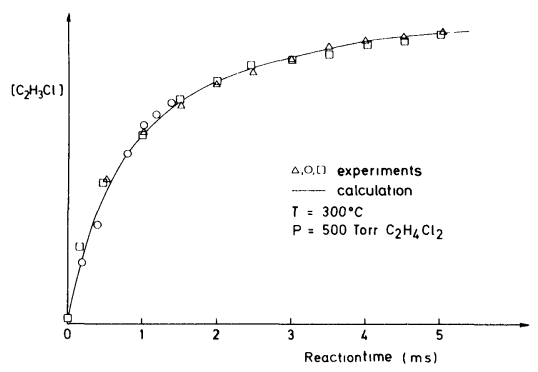

$\mathrm{k}\left(\mathrm{cm}^{3} \mathrm{~mol}^{-1} \mathrm{~s}^{-1}\right)$

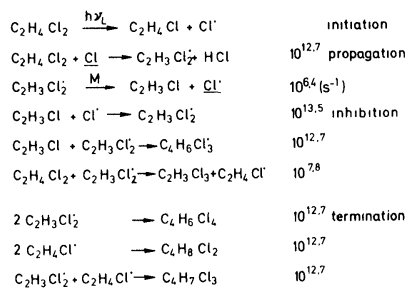

FIGURE 11 Formation of $\mathrm{C}_{2} \mathrm{H}_{3} \mathrm{Cl}$ by UV-laser induced radical chain reaction. 
identical effects like adiabatic cooling or vinyl chloride inhibition and it could be achieved only by a drastic reduction of laser energy. At the highest temperature studied $(720 \mathrm{~K})$ and a low laser energy of $1 \mathrm{~mJ} / \mathrm{cm}^{2}$ we obtained quantum yields of more than $10^{4}$. It was possible to extract the rate constant of the unimolecular reaction

$$
\mathrm{C}_{2} \mathrm{H}_{3} \mathrm{Cl}_{2}+\mathrm{M} \longrightarrow \mathrm{C}_{2} \mathrm{H}_{3} \mathrm{Cl}+\mathrm{Cl}+\mathrm{M}
$$

from the time constant of the total reaction. A series of experiments with fixed temperature and pressure and varying irradiation intensity showed that the decrease of the chain length with higher initial radical concentration is paralleled by the increase of reaction time so that the arithmic product of both remains constant over the whole range of laser energy. Figure 12 compiles data for the change of the unimolecular rate constant $k_{5}$ when an inert gas $\left(\mathrm{N}_{2}\right)$ was added to 60 torr of DCE up to a total pressure of 600 torr. The reaction rate is strongly pressure dependent in this region. In the double logarithmic plot log $k / \log p$ one gets a straight line with a slope of 0.52 . An Arrhenius diagram of the measurements at 300 torr DCE between 520 and $720 \mathrm{~K}$ (see Figure 13) shows a decline of activation energy with temperature. This may be explained by two reasons. First, when

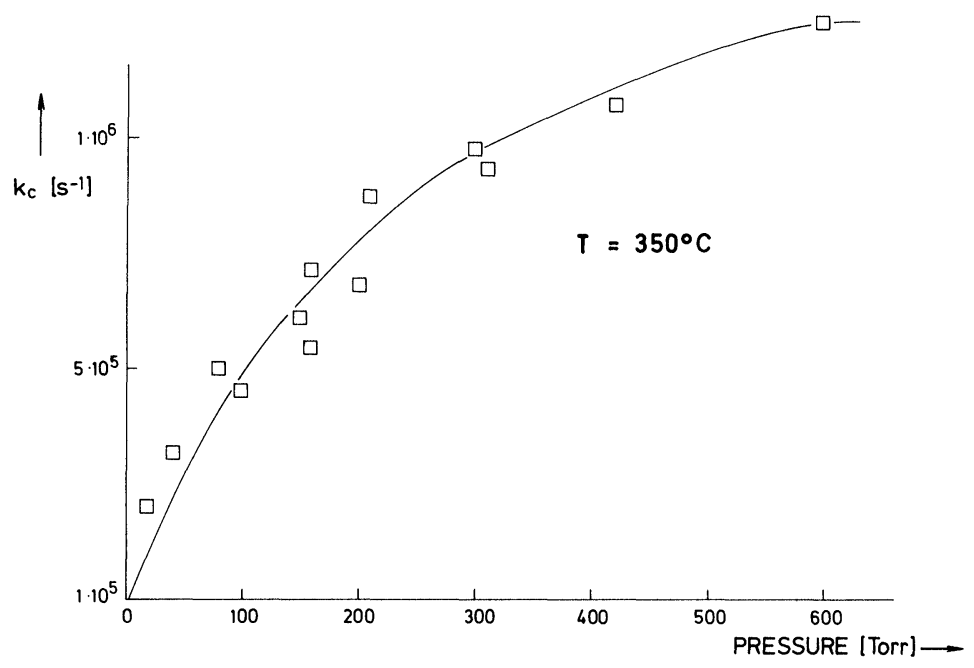

FIGURE 12 Pressure dependence of VC formation by radical chain reactions. 


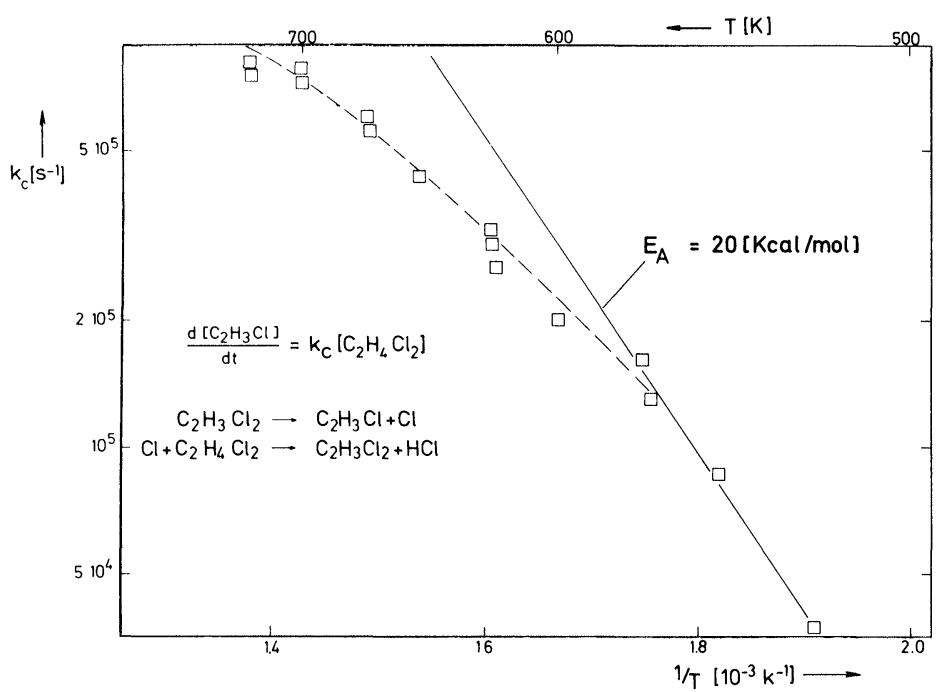

FIGURE 13 Temperature dependence of $\mathrm{VC}$ formation rate by radical chain reaction.

moving to higher temperatures the unimolecular reaction shifts into its second order region where the activation energy is lower, and secondly, at higher temperatures $k_{5}$ is so accelerated that it is not strictly the rate determining step anymore though it is still a factor of 5 slower than reaction

$$
\mathrm{Cl}+\mathrm{C}_{2} \mathrm{H}_{4} \mathrm{Cl}_{2} \longrightarrow \mathrm{HCl}+\mathrm{C}_{2} \mathrm{H}_{3} \mathrm{Cl}_{2}
$$

Therefore it follows that the low temperature values should be taken to determine the Arrhenius parameters. In this region $520-570 \mathrm{~K}$ one gets the expression

$$
k_{5}=(6.5 \pm 2) \cdot 10^{13} \exp (-83 \pm 3 \mathrm{~kJ} / \mathrm{mol} / \mathrm{RT})
$$

With the rate data on the pressure and temperature dependence of $k_{5}$ obtained in this investigation one can use the computer stimulation model (see Figure 11) to predict the effect of laser generated free radicals in the DCE to VC conversion at conditions used in the technical process (see Figure 14). These calculations show that a significant increase in the conversion ratio can be obtained by laser photocatalysis. 


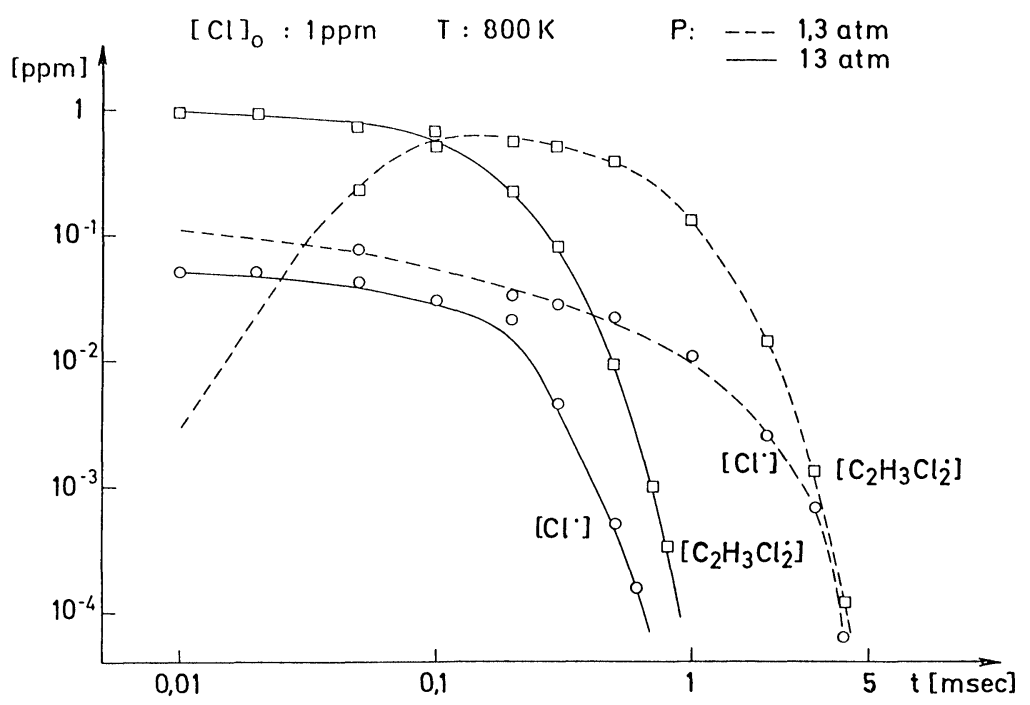

FIGURE 14 Calculated time profiles for laser induced radical concentrations in the DCE to VC conversions at different reactor conditions.

\section{Acknowledgement}

The authors wish to thank Prof. H. Gg. Wagner for his continuous interest in this work and Prof. J. Troe or many helpful discussions. The financial support of the Deutsche Forschungsgemeinschaft (SFB 93) is gratefully acknowledged.

\section{References}

1. P. Andresen, A. Jacobs, C. Kleinermann and J. Wolfrum, Nineteenth Symposium on Combustion (The Combustion Institute, 1983) to be published.

2. J. L. Chidsey and D. R. Crosley, J. Quant. Spectrosc. Radiat. Transfer, 23, 187-199 (1980).

3. B. Lin, Private Communication.

4. R. A. Sutherland and R. A. Anderson, J. Chem. Phys. 58, 1226 (1973).

5. R. S. Mulliken, J. Chem. Phys. 8, 382 (1940).

6. S. N. Foner and R. L. Hudson, J. Chem. Phys. 36, 2681 (1962).

7. P. Pechukas, J. C. Light and C. Rankin, J. Chem. Phys. 44, 794 (1966); calculated assuming $b_{\max }=1.8 \AA$ obtained from trajectory calculation at $60 \mathrm{kcal} / \mathrm{mol}$ collision energy on an ab initio- $\mathrm{HO}_{2}$ surface.

8. C. Follelius and R. J. Blint, Chem. Phys. Lett. 64, 183 (1979).

9. G. C. Light and J. H. Matsumoto, Chem. Phys. Lett. 58, 578 (1979).

10. B. Bernstein and R. D. Levine, in: Advances in Atomic and Molecular Physics, Vol. 11, ed. D. R. Bates and B. Bederson (Academic, New York, 1975) p. 215. 
11. J. E. Spencer, J. Endo, G. P. Glass 16th Int. Symp. Combustion (Combustion Inst., Pittsburgh, 1977) p. 829.

12. R. J. Zellner, Phys. Chem. 83, 18 (1979).

13. H. M, Crosswhite and G. H. Dieke, J. Quant. Spectrosc. Radiat. Transfer 2, 97 (1962).

14. W. D. Gwinn, B. E. Turner, W. Miller Goss and G. L. Blackman, Astrophys. J. 179, 789 (1973); S. Green and R. N. Zare, Chem. Phys. 7, 62 (1975).

15. A. C. Luntz, J. Chem. Phys. 73, 1143 (1980).

16. J. A. Miller, J. Chem. Phys. 74, 5120 (1981).

17. H. Johnston and R. Graham, J. Phys. Chem. 77, 62 (1973).

18. R. Schmiedl, H. Dugan, W. Meier and K. H. Welge, J. Phys. A 304, 137 (1982).

19. R. S. Sheorey and G. W. Flynn, J. Chem. Phys. 72, 1175 (1980).

20. G. Graner, J. Phys. Chem. 83, 1491 (1979).

21. Ch. K. Rhodes (ed.), Excimer Lasers, Top. in Appl. Phys., Vol. 30 (Springer, Heidelberg, 1979).

22. J. Wolfrum, M. Kneba, P. Clough and M. Schneider, German Patent (DBP $29383537)$.

23. F. O. Rice and K. F. Herzfeld, J.A.C.S. 56, 284 (1934). 